\title{
Novel predictive biomarkers for cervical cancer prognosis
}

\author{
PABLO MORENO-ACOSTA ${ }^{1}$, SCHYRLY CARRILLO $^{1}$, OSCAR GAMBOA $^{2}$, \\ ALFREDO ROMERO-ROJAS ${ }^{3}$, JINNETH ACOSTA ${ }^{4}$, MONICA MOLANO ${ }^{5}$, \\ JOSEPH BALART-SERRA ${ }^{6}$, MARTHA COTES ${ }^{7}$, CHLOÉ RANCOULE $^{8}$ and NICOLAS MAGNÉ ${ }^{8,9}$ \\ ${ }^{1}$ Research Group in Cancer Biology, Research Group in Radiobiology Clinical, Molecular and Celular; ${ }^{2}$ Analysis Unit; \\ ${ }^{3}$ Pathological Oncology Group, National Cancer Institute; ${ }^{4}$ Pathology Group, National University of Colombia, Bogotá, \\ Colombia; ${ }^{5}$ Microbiology and Infection Diseases, The Royal Women's Hospital, Melbourne, Victoria, Australia; \\ ${ }^{6}$ Radiation Oncology Department, SanPau Hospital, Barcelona, Spain; ${ }^{7}$ Department of Radiotherapy, National Cancer Institute, \\ Bogotá, Colombia; ${ }^{8}$ Department of Radiotherapy, Lucien Neuwirth Cancer Institute, Saint Priest En Jarez; \\ ${ }^{9}$ Laboratory of Radiobiology, EMR3738, Faculty of Medicine Lyon Sud, Pierre Bénite, France
}

Received May 13, 2016; Accepted July 7, 2016

DOI: $10.3892 / \mathrm{mco} .2016 .1055$

\begin{abstract}
High hypoxic, glycolytic and acidosis metabolisms characterize cervical cancer tumors and have been described to be involved in chemoradioresistance mechanisms. Based on these observations, the present study assessed four selected novel biomarkers on the prognosis of locally advanced cervical carcinoma. A total of 66 patients with stage IIB/IIIB cervical cancer were retrospectively included. The protein expression levels of glucose transporter 1 (GLUT1), carbonic anhydrase 9 (CAIX) and hexokinase 1 (HKII) were investigated by immunohistochemistry on tumor biopsies, hemoglobin was measured and the disease outcome was monitored. A total of 53 patients $(80.3 \%)$ presented a complete response. For these patients, the protein expression levels of GLUT1, CAIX and HKII were overexpressed. A significant difference was observed $(\mathrm{P}=0.0127)$ for hemoglobin levels $(\leq 11 \mathrm{~g} / \mathrm{dl})$ in responsive compared with non-responsive patients. The expression of GLUT1 is associated with a lower rate of both overall and disease-free survival, with a trend of decreased risk of 1.1x and 1.5x, respectively. Co-expression of GLUT1 and HKII is associated with a decreased trend risk of 1.6x for overall survival. Patients with hemoglobin levels $\leq 11 \mathrm{~g} / \mathrm{dl}$ had a 4.3-fold risk $(\mathrm{P}=0.02)$ in decreasing both to the rate of overall and disease-free survival. The presence of anemic hypoxia (hemoglobin $\leq 11 \mathrm{~g} / \mathrm{dl}$ ) and the expression of GLUT1 and/or HKII influence treatment response and are associated with a lower overall and disease-free survival. The present results demonstrated that these biomarkers may be used as predictive
\end{abstract}

Correspondence to: Professor Nicolas Magné, Department of Radiotherapy, Lucien Neuwirth Cancer Institute, 108bis Avenue Albert Raimond, 42270 Saint Priest En Jarez, France

E-mail: nicolas.magne@icloire.fr

Key words: cervical cancer, biomarkers, carbonic anhydrase IX, glucose transporter type 1, hexokinase, anemic hypoxia markers and suggested that these metabolic pathways can be used as potential novel therapeutic targets.

\section{Introduction}

The proposed model for the development of cervical cancer involves the involvement of phenotypes, including glycolytic, hypoxic and acidosis. Previous experimental and clinical studies have shown that cervical cancer tumors are characterized by a highly hypoxic metabolism (1-5) and a high rate of glycolysis $(2,6-8)$. Additionally, these high hypoxic, glycolytic and acidosis metabolisms are implicated in resistance to treatments, including radiotherapy and chemotherapy. These phenotypes are associated with genetic instability, which may be reflected by the increased expression of certain proteins, including glucose transporter 1 (GLUT1), carbonic anhydrase 9 (CAIX) and hexokinase 1 (HKII) (3,8-10). These proteins are considered as potential prognostic markers of disease progression, metastasis and survival. GLUT1, also termed SLC2A, is part of a family composed of 14 GLUT proteins (glucose transporters). Their expression is dually controlled via hypoxia inducible factor (HIF)-1 in response to reduced oxidative phosphorylation (11) and by the Akt/PI3K signaling pathway, which is activated by insulin and growth factors induced by glucose metabolism $(12,13)$. CAIX is considered an endogenous marker of hypoxia, a condition that increases its expression levels, thus leading to acidosis (decreased extracellular $\mathrm{pH}$ ). CAIX is regulated by HIF-1 $(14,15)$ and may also depend on factors including low levels of glucose, which prevents its expression $(14,16,17)$, low levels of bicarbonate and cellular density $(14,18)$. HKII is involved in the conversion of glucose to glucose-6-phosphate for glycolysis $(19,20)$. It serves a role in apoptosis and inhibition of cell death by binding and stabilizing the mitochondrial membrane. Therefore, it is hypothesized that its increased activity assists with the maintenance of the malignant cell phenotype $(9,10,21,22)$.

The presence of hypoxia in solid tumors is a concern in clinical practice as a result of its negative impact on the 
prognosis and treatment response in cancer. Both experimental and clinical studies suggest a direct association between the decrease in hemoglobin ( $\mathrm{Hgb}$ ) levels and decreased oxygenation in the tumor (23). In squamous cell carcinoma, as with cervical cancer, it is noted that the maximum level of oxygenation occurs when the $\mathrm{Hgb}$ range is between 12 and $14 \mathrm{~g} / \mathrm{dl}$. Hgb levels $<11 \mathrm{~g} / \mathrm{dl}$ are directly associated with tumor hypoxia (24-26). Under this condition, in cervical cancer, low levels of hemoglobin (anemia) have been associated with poor local control of the disease $(16,25)$ and low survival rates $(4,27)$. However, it is controversial whether $\mathrm{Hb}$ is a prognostic factor in cancer; a significant correlation with tumor hypoxia ( $\mathrm{pO} 2$ $<5 \mathrm{mg}$ ) prior to radiotherapy or radiochemotherapy in cervical cancer remains to be established (25).

Certain previous studies reportd that GLUT1, CAIX, HKII and Hgb level can be considered as biomarkers, suggesting they can be used as prognostic markers for improved therapeutic management of cervical cancer $(1,6)$. The purpose of the present study was to determine whether baseline expression of GLUT1, CAIX and HKII, as well as pre- and post-treatment $\mathrm{Hgb}$ levels are associated with treatment response and survival in cancer patients with locally advanced cervical carcinoma.

\section{Materials and methods}

Study design, selection and patient characteristics. The present study was a retrospective study in a prospective data bank. Between January 2001 and December 2007, 66 patients were selected with locally advanced cervical carcinoma staged IIB (n=24) and IIIB (n=42) according to the International Federation of Gynecology and Obstetrics. These patients were treated at the National Cancer Institute (Bogota, Colombia). The histological types were squamous cell carcinoma in all cases. The median age was 47 years, ranging between 26 and 72. A performance status of $0-1$ was observed in $65 / 66$ patients. The protocols followed in the present study were consistent with medical standards of practice and administrative techniques for health research from the Ministry of Health Colombia. Each patient was first informed of the objectives of the study and voluntarily agreed to take part by signing the informed consent, previously approved by the Ethics Committee of Neuwirth Cancer Institute (Saint Priest En Jarez, France).

The clinicopathological characteristics of the patients, as conditions and parameters considered for the making and reading of the immunohistochemistry to GLUT1, CAIX and HKII, were previously described (1). With regards to the expression of GLUT1, CAIX and HKII, a greater increase was observed for the expression of GLUT-1 (74\%), followed by CAIX (41\%) and HKII (18\%).

Treatment. All 66 patients included in the present study underwent radiotherapy. Treatment consisted of pelvic external beam radiotherapy (EBRT) using 6-18 MV photons with a standard four-field technique, delivering a total dose of $45 \mathrm{~Gy}$ in 25 fractions $(1.8 \mathrm{~Gy} /$ fraction on 5 consecutive days/week with an overall EBRT treatment time of 5 weeks). Following the initial EBRT, an intracavitary brachytherapy-boost of 35 Gy at point A was delivered, according the International Commission on Radiation Units and Measurements (ICRU). A total of 44 patients received weekly concomitant chemotherapy (cisplatin, $40 \mathrm{mg} / \mathrm{m}^{2}$ ) and 22 patients treated with radiotherapy alone.

Assessment of response. Follow-up was scheduled 6 weeks following the completion of EBRT, and then every 3 months during the subsequent 5 years. Complete response was defined as an absence of residual disease at clinical examination and radiological imaging 3 months after the completion of treatment. The responder group was defined as the group of patients who presented complete response and the non-responder group was the patients that presented partial response, stable disease or tumor progression.

Statistical analysis. Statistical analysis was performed using SPSS 18.0 (IBM SPSS, Chicago, IL, USA) and Stata 11.1 software (National Cancer Institute, Bogota, Colombia). The present study calculated measures of central tendency and dispersion for continuous variables, and proportions for categorical variables. Correlations between the levels of $\mathrm{Hgb}$, the expression levels of GLUT1, CAIX and HKII, and the outcome during follow-up were analyzed using Kaplan-Meier survival tests and the differences were calculated using the log-rank test. To determine which variables were associated with survival, a Cox regression model was constructed, calculating crude and adjusted hazard ratio. Variables with significant results in the test log-rank test and those with biological plausibility were used for adjustment. Analyses were two-tailed. $\mathrm{P} \leq 0.05$ were considered to indicate a statistically significant difference.

\section{Results}

A total of 53 patients (80.3\%) exhibited a complete response. Non-responders, based on concomitant chemotherapy or not, were as follows: 6/22 (27.2\%) and 7/44 (15.9\%) patients revealed no response with exclusive radiotherapy and radiochemotherapy, respectively.

When comparing the Hgb levels, a significantly higher average $\mathrm{Hgb}$ level was observed in the complete response group compared with the no response group (Fig. 1). The average levels of Hgb were: $12.7 \mathrm{~g} / \mathrm{dl}$ (range, 5.2-16.0) for the complete response group and $10.6 \mathrm{~g} / \mathrm{dl}$ (range, 4.3-15.3) for the no response group. Pre-treatment $\mathrm{Hgb} \leq 11 \mathrm{~g} / \mathrm{dl}$ was associated with non-response to treatment in univariate logistic regression analysis [odds ratio $(\mathrm{OR})=3.99 ; 95 \%$ confidence intervals $(\mathrm{CI})=1.13-14.14 ; \mathrm{P}=0.032]$. In multivariate analyses, the risk was close to significance $(\mathrm{OR}=4.31 ; 95 \% \mathrm{CI}=0.89-20.93$; $\mathrm{P}=0.05)$. No significant difference between post-treatment hemoglobin levels and response to treatment (data not shown).

There was no significant difference was observed for the expression levels of GLUT, HKII and CAIX. The following characteristics appeared to have a tendency to no response: Stage IIIB $(\mathrm{OR}=2.19)$, keratinizing tumors $(\mathrm{OR}=1.42)$, poorly differentiated tumors-G3 $(\mathrm{OR}=1.33)$, tumors $>4 \mathrm{~cm}$ $(\mathrm{OR}=2.13)$, bilateral involvement of parametrium $(\mathrm{OR}=1.48)$, receive exclusive radiotherapy $(\mathrm{OR}=1.98)$ and high dose rate brachytherapy $(\mathrm{OR}=1.69)$.

Cox-model analysis on factors influencing disease-free survival (DFS) and overall survival (OS) are presented in Table I. Only two factors were associated with a decrease 
Table I. Cox analysis of disease-free survival and global survival.

Multivariate analysis ${ }^{\mathrm{a}}$

\begin{tabular}{|c|c|c|c|c|c|c|}
\hline \multirow[b]{3}{*}{ Variable } & \multirow{2}{*}{\multicolumn{3}{|c|}{ Disease-free survival }} & & & \\
\hline & & & & \multicolumn{3}{|c|}{ Global survival } \\
\hline & $\mathrm{HR}$ & $95 \% \mathrm{CI}$ & P-value & $\mathrm{HR}^{\mathrm{a}}$ & $95 \% \mathrm{CI}$ & P-value \\
\hline \multicolumn{7}{|l|}{ Treatment response } \\
\hline Complete response & 1.00 & & & 1.00 & & \\
\hline No response & 34.70 & $7.95-151.45$ & 0.00 & 40.6 & $8.10-203.5$ & 0.00 \\
\hline \multicolumn{7}{|l|}{ FIGO } \\
\hline IIB & 1.00 & & & 1.00 & & \\
\hline IIIB & 0.31 & $0.75-1.33$ & 0.12 & 0.22 & $0.04-1.13$ & 0.07 \\
\hline \multicolumn{7}{|l|}{ Differentiation grade } \\
\hline G1 & 1.00 & & & 1.00 & & \\
\hline $\mathrm{G} 2$ & 5.07 & $0.38-68.28$ & 0.22 & 2.57 & $0.15-44.9$ & 0.52 \\
\hline G3 & 1.72 & $0.70-42.11$ & 0.74 & 1.49 & $0.051-43.23$ & 0.82 \\
\hline \multicolumn{7}{|l|}{ Tumor keratinization } \\
\hline Presence & 1.00 & & & 1.00 & & \\
\hline Absence & 2.48 & $0.42-14.63$ & 0.32 & 2.37 & $0.29-19.44$ & 0.42 \\
\hline \multicolumn{7}{|l|}{ Parametrial commitment } \\
\hline Unilateral & 1.00 & & & 1.00 & & \\
\hline Bilateal & 2.49 & $0.63-9.78$ & 0.19 & 2.04 & $0.47-8.84$ & 0.33 \\
\hline \multicolumn{7}{|l|}{ Tumor size $>4 \mathrm{~cm}$} \\
\hline No & 1.00 & & & 1.00 & & \\
\hline Yes & 1.22 & $0.12-12.06$ & 0.86 & 1.01 & $0.097-10.59$ & 0.99 \\
\hline \multicolumn{7}{|l|}{$\mathrm{Hgb} \leq 11 \mathrm{~g} / \mathrm{dl}$} \\
\hline No & 1.00 & & & 1.00 & & \\
\hline Yes & 4.33 & $1.22-15.44$ & 0.02 & 4.33 & $0.88-21.33$ & 0.05 \\
\hline \multicolumn{7}{|l|}{ Treatment type } \\
\hline Concurrent radiochemotherapy & 1.00 & & & 1.00 & & \\
\hline Exclusive radiotherapy & 3.02 & $0.63-14.45$ & 0.17 & 4.58 & $0.67-31.50$ & 0.12 \\
\hline \multicolumn{7}{|l|}{ Brachytheraphy } \\
\hline Low-dose rate & 1.00 & & & 1.00 & & \\
\hline High-dose rate & 0.74 & $0.17-3.25$ & 0.69 & 1.07 & $0.19-6.09$ & 0.94 \\
\hline \multicolumn{7}{|l|}{ Protein expression } \\
\hline Negative & 1.00 & & & 1.00 & & \\
\hline GLUT1 & 1.50 & $0.37-2.48$ & 0.12 & 1.12 & $0.411-3.04$ & 0.16 \\
\hline GLUT1 and CAIX & 0.89 & $0.21-3.65$ & 0.87 & 0.89 & $0.18-4.28$ & 0.88 \\
\hline GLUT1 and HKII & 1.60 & $0.19-4.24$ & 0.14 & 0.90 & $0.25-5.60$ & 0.90 \\
\hline GLUT1, CAIX and HKII & 0.15 & $0.01-2.01$ & 0.15 & 0.013 & $0.00-0.59$ & 0.03 \\
\hline
\end{tabular}

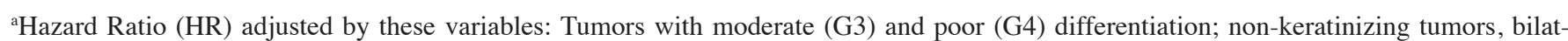
eral compromiso parametria, tumor size $>4 \mathrm{~cm}, \mathrm{Hb} \leq 11 \mathrm{~g} / \mathrm{dl}$, receive exclusive radiotherapy and brachytherapy high rate. Expression or co-expression of GLUT1 and CAIX HKII proteins. Hgb, hemoglobin; GLUT1, glucose transporter 1; CAIX, carbonic anhydrase 9; HKII, hexokinase 1; HR, hazard ratio; CI, confidence interval.

of DFS: Low levels of hemoglobin $\leq 11 \mathrm{~g} / \mathrm{dl}(\mathrm{OR}=4.33)$ and no response to treatment $(\mathrm{OR}=34.7)$. No response to treatment was associated with an unfavorable outcome on OS $(\mathrm{OR}=40.6)$. Other factors appeared to have a tendency towards OS: Stage IIIB, keratinizing tumors, tumors $>4 \mathrm{~cm}$, bilateral involvement of parametrium, management with exclusive radiotherapy, moderate $\mathrm{G} 2$ and poor $\mathrm{G} 3$ differentiation.
A significantly positive impact on the $\mathrm{OS}(\mathrm{OR}=0.013)$ and DFS $(\mathrm{OR}=0.15)$ was observed with the expression levels of GLUT1, CAIX and HKII when all three markers were expressed (Table I). No significant influence on the OS and DFS was observed from individual marker expression. The 5-year DFS and OS rates were 60 and 62.5\%, respectively, among patients with GLUT1 expression. By contrast, the DFS 


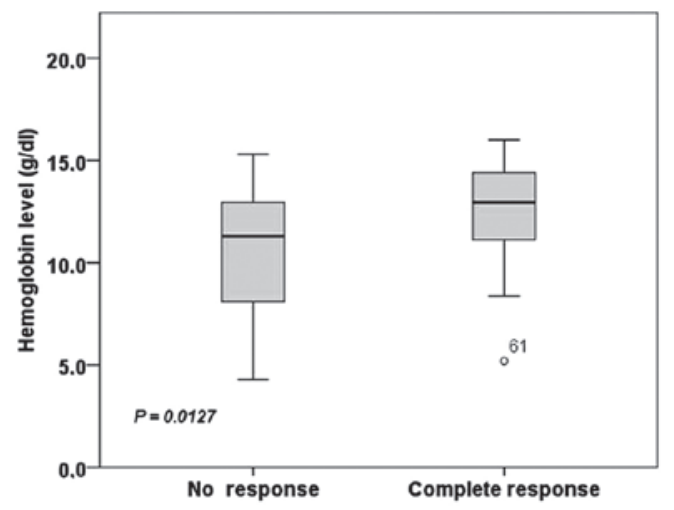

Figure 1. Hemoglobin levels and treatment response. The point 61 denotes an outlier that was verified.

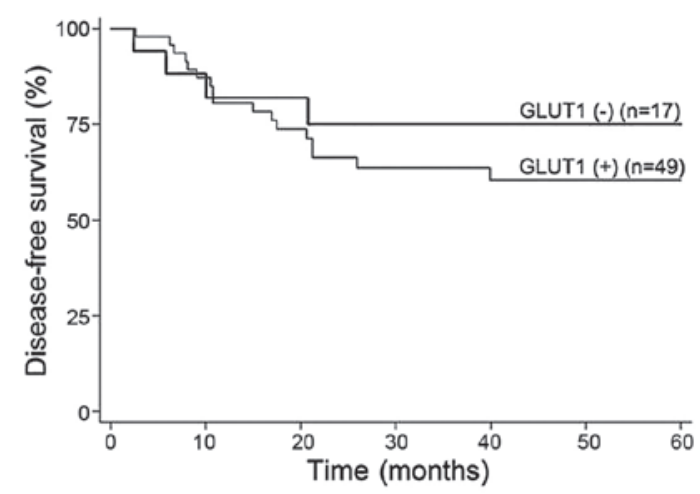

Figure 2. Disease-free survival and GLUT1 expression. Kaplan-Meier survival curves were produced, according to protein expression of GLUT1. GLUT1, glucose transporter 1 .

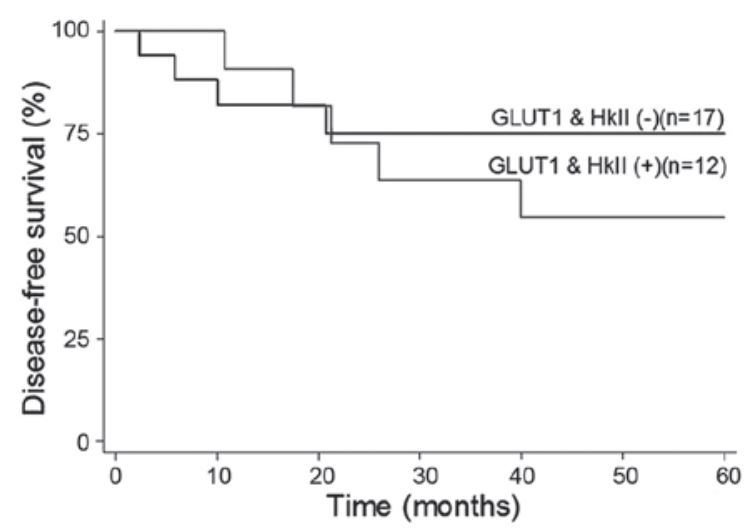

Figure 3. Disease-free survival and the co-expression of GLUT1 and HKII. Kaplan-Meier survival curves were produced, according to the protein expression levels of GLUT1 and HKII. GLUT1, glucose transporter 1; HKII, hexokinase II.

and OS were 75 and $60 \%$, respectively, among those with no GLUT1 expression (Fig. 2). The DFS and OS rates were both 55\% among patients with GLUT1 and HKII co-expression, whereas the DFS and OS were 75 and $62.5 \%$, respectively, among those with no GLUT1 and HKII co-expression (Fig. 3). The DFS and OS were 75 and $62.5 \%$, respectively, among those without co-expression of GLUT1 and HKII.

\section{Discussion}

The present study evaluated whether baseline expression levels of GLUT1, CAIX and HKII, and Hgb levels, were associated with treatment response and survival in patients with locally advanced cervical carcinoma.

A number of patients do not respond adequately in the management of invasive cervical cancer, and this number increases when treated with exclusive radiotherapy compared with radiochemotherapy, a situation observed in the present study. A potential survival benefit of $12 \%$ is attributable to the use of chemoradiotherapy (28). This confirms the recommendation made by the American Society of Clinical Oncology, which advises to privilege concomitant radiochemotherapy for patients with locally advanced cervical cancer.

No response to treatment, as in the 13 reported cases, may be explained by two reasons: The first is based on squamous cell carcinoma, including cervical cancer, and are characterized by having a marked ability to repopulate with rapidly dividing cells replacing those who die by radiation or chemical agents (29). The other possible explanation is related to the involvement of different pre-existing factors that may be involved in the response to treatment, including low Hgb levels (anemia), low immune function, tumor status (e.g. the degree of differentiation), the tumor micro-environment that meets tumor hypoxia, increased glycolysis and extracellular acidosis (10,30-33).

The presence of hypoxia in solid tumors is a concern at the clinical level due to its negative impact on the prognosis and treatment response. Previous experimental and clinical studies suggest that there is a direct association between the decrease in Hgb levels and decreased oxygenation in a tumor (23). In squamous cell carcinoma, like that of the cervix, the prognostic impact of anemia is well-established (23). The present study revealed that $\mathrm{Hgb}$ levels $<11 \mathrm{~g} / \mathrm{dl}$ pretreatment, were observed in the group of patients who did not present complete response to exclusive radiotherapy. The results of the comparative analysis demonstrated a significant difference $(\mathrm{P}=0.0127)$ between the levels of Hgb in patients with no response compared with the complete response group. Multivariate analysis revealed a close risk to the significance for patients with anemia that failed to respond to exclusive radiotherapy. This finding was consistent with reports that it is considered that anemia is a risk factor predictive of treatment outcome (23), since it has been associated with an unfavorable local control of disease $(16,25,26)$ and low survival rates $(4,25,27)$. Retrospective studies, similar to the present study, show that those patients with Hgb levels $<11 \mathrm{~g} / \mathrm{dl}$ have a high risk of reducing DFS, which can be improved with the correction of the anemia (25).

Direct measurement of oxygen levels in tumor tissues presents technical limitations, which has promoted the use of endogenous and exogenous markers associated with tumor hypoxia, endogenous markers including hypoxia-related proteins (HIF-1 $\alpha$, GLUT-1, CAIX) and exogenous markers including bio-reductive drugs (34-36). In the evaluation of GLUT 1 and CAIX in this study, tumor hypoxia was measured indirectly. We observed differences in their levels of expression, the expression of GLUT-1 was higher compared to CAIX; This result suggests that the tumors showed episodic hypoxia possibly due to intratumoral heterogeneity. These findings 
suggested an effect of GLUT1 associated with response to treatment. These results supported the hypothesis that a combination of biomarkers is more robust compared with a single marker, so further work is required to confirm the usefulness of incorporating multiple biomarkers to identify patients with hypoxic tumors for future targeting (37). Further prospective studies are required to confirm the present results. The study and detection of these markers may contribute to determining the metabolic and hypoxic state of tumors, allowing the optimization of the therapeutic management by considering such markers as predictive markers and/or molecular targets.

\section{References}

1. Moreno-AcostaP,Carrillo S, GamboaO,Acosta Y,Balart-Serrad J, Magne N, Melo-Uribef MA and Romero-Rojas AE: Expresión de marcadores hipóxicos y glucolíticos CAIX, GLUT-1, HKII y su relación con la respuesta temprana al tratamiento en carcinoma escamocelular de cuello uterino. Progresos de Obstetricia y Ginecología 56: 404-413, 2013.

2. DeBerardinis RJ, Lum JJ, Hatzivassiliou G and Thompson CB The biology of cancer: Metabolic reprogramming fuels cell growth and proliferation. Cell Metab 7: 11-20, 2008.

3. Waggoner SE: Cervical cancer. Lancet 361: 2217-2225, 2003.

4. Vaupel P and Harrison L: Tumor hypoxia: Causative factors, compensatory mechanisms and cellular response. Oncologist 9 (Suppl 5): S4-S9, 2004

5. Pili R and Donehower RC: Is HIF-1 alpha a valid therapeutic target? J Natl Cancer Inst 95: 498-499, 2003.

6. Gatenby RA and Gillies RJ: Glycolysis in cancer: A potential target for therapy. Int J Biochem Cell Biol 39: 1358-1366, 2007.

7. Lamkin DM, Spitz DR, Shahzad MM, Zimmerman B, Lenihan DJ, Degeest K, Lubaroff DM, Shinn EH, Sood AK and Lutgendorf SK: Glucose as a prognostic factor in ovarian carcinoma. Cancer 115: 1021-1027, 2009.

8. Fan Y and Zong WX: Hacking hexokinase halts tumor growth. Cancer Biol Ther 7: 1136-1138, 2008.

9. Lee WY, Huang SC, Hsu KF, Tzeng CC and Shen WL: Roles for hypoxia-regulated genes during cervical carcinogenesis: Somatic evolution during the hypoxia-glycolysis-acidosis sequence. Gynecol Oncol 108: 377-384, 2008.

10. Xue F, Lin LL, Dehdashti F, Miller TR, Siegel BA and Grigsby PW: F-18 fluorodeoxyglucose uptake in primary cervical cancer as an indicator of prognosis after radiation therapy. Gynecol Oncol 101: 147-151, 2006.

11. Behrooz A and Ismail-Beigi F: Dual control of glut1 glucose transporter gene expression by hypoxia and by inhibition of oxidative phosphorylation. J Biol Chem 272: 5555-5562, 1997.

12. Hatzivassiliou G, Andreadis C and Thompson CB: Akt-directed metabolic alterations in cancer. Drug Discovery Today: Disease Mechanisms 2: 255-262, 2005.

13. Gottlob K, Majewski N, Kennedy S, Kandel E, Robey RB and Hay N: Inhibition of early apoptotic events by Akt/PKB is dependent on the first committed step of glycolysis and mitochondrial hexokinase. Genes Dev 15: 1406-1418, 2001.

14. Mayer A, Höckel M and Vaupel P: Endogenous hypoxia markers: Case not proven! Adv Exp Med Biol 614: 127-136, 2008.

15. Lal A, Peters H, St Croix B, Haroon ZA, Dewhirst MW, Strausberg RL, Kaanders JH, van der Kogel AJ and Riggins GJ: Transcriptional response to hypoxia in human tumors. J Natl Cancer Inst 93: 1337-1343, 2001.

16. Rafajová M, Zatovicová M, Kettmann R, Pastorek J and Pastoreková S: Induction by hypoxia combined with low glucose or low bicarbonate and high posttranslational stability upon reoxygenation contribute to carbonic anhydrase IX expression in cancer cells. Int J Oncol 24: 995-1004, 2004.

17. Vordermark D, Kaffer A, Riedl S, Katzer A and Flentje M: Characterization of carbonic anhydrase IX (CA IX) as an endogenous marker of chronic hypoxia in live human tumor cells. Int J Radiat Oncol Biol Phys 61: 1197-1207, 2005.

18. Pastorek J, Pastoreková S Callebaut I, Mornon JP, Zelník V, Opavský R, Zat'ovicová M, Liao S, Portetelle D, Stanbridge EJ, et al: Cloning and characterization of MN, a human tumor-associated protein with a domain homologous to carbonic anhydrase and a putative helix-loop-helix DNA binding segment. Oncogene 9: 2877-2888, 1994.
19. Lyshchik A, Higashi T, Hara T, Nakamoto Y, Fujimoto K, Doi R, Imamura M, Saga T and Togashi K: Expression of glucose transporter-1, hexokinase-II, proliferating cell nuclear antigen and survival of patients with pancreatic cancer. Cancer Invest 25: 154-162, 2007.

20. Pouysségur J, Dayan F and Mazure NM: Hypoxia signalling in cancer and approaches to enforce tumour regression. Nature 441: 437-443, 2006.

21. Mathupala SP, Ko YH and Pedersen PL: Hexokinase II: Cancer's double-edged sword acting as both facilitator and gatekeeper of malignancy when bound to mitochondria. Oncogene 25: 4777-4786, 2006.

22. Oh JM, Ryoo IJ, Yang Y, Kim HS, Yang KH and Moon EY: Hypoxia-inducible transcription factor (HIF)-1 alpha stabilization by actin-sequestering protein, thymosin beta-4 (TB4) in Hela cervical tumor cells. Cancer Lett 264: 29-35, 2008.

23. Dunst J, Kuhnt T, Strauss HG, Krause U, Pelz T, Koelbl H and Haensgen G: Anemia in cervical cancers: Impact on survival, patterns of relapse, and association with hypoxia and angiogenesis. Int J Radiat Oncol Biol Phys 56: 778-787, 2003.

24. Chang CC, Murphy SP and Ferrone S: Differential in vivo and in vitro HLA-G expression in melanoma cells: Potential mechanisms. Hum Immunol 64: 1057-1063, 2003.

25. Winter WE III, Maxwell GL, Tian C, Sobel E, Rose GS, Thomas G and Carlson JW: Association of hemoglobin level with survival in cervical carcinoma patients treated with concurrent cisplatin and radiotherapy: A gynecologic oncology group study. Gynecol Oncol 94: 495-501, 2004.

26. Mayer A, Höckel M and Vaupel P: Carbonic anhydrase IX expression and tumor oxygenation status do not correlate at the microregional level in locally advanced cancers of the uterine cervix. Clin Cancer Res 11: 7220-7225, 2005.

27. Haensgen G, Krause U, Becker A, Stadler P, Lautenschlaeger C, Wohlrab W, Rath FW, Molls M and Dunst J: Tumor hypoxia, p53, and prognosis in cervical cancers. Int J Radiat Oncol Biol Phys 50: 865-872, 2001.

28. Green J, Kirwan J, Tierney J, Vale C, Symonds P, Fresco L, Williams C and Collingwood M: Concomitant chemotherapy and radiation therapy for cancer of the uterine cervix. Cochrane Database Syst Rev: CD002225, 2005.

29. Symonds R and Foweraker K: Principles of chemotherapy and radiotherapy. Current Obstetrics \& Gynaecology 16: 100-106, 2006.

30. Airley RE, Loncaster J, Raleigh JA, Harris AL, Davidson SE, Hunter RD, West CM and Stratford IJ: GLUT-1 and CAIX as intrinsic markers of hypoxia in carcinoma of the cervix: Relationship to pimonidazole binding. Int J Cancer 104: 85-91, 2003.

31. Bachtiary B, Schindl M, Pötter R, Dreier B, Knocke TH, Hainfellner JA, Horvat R and Birner P: Overexpression of hypoxia-inducible factor 1alpha indicates diminished response to radiotherapy and unfavorable prognosis in patients receiving radical radiotherapy for cervical cancer. Clin Cancer Res 9: 2234-2240, 2003.

32. Moreno-Acosta P, Gamboa O, Sanchez de Gomez M, Cendales R, Diaz GD, Romero A, Balart Serra J, Conrado Z, Levy A, Chargari $C$ and Magné N: IGF1R gene expression as a predictive marker of response to ionizing radiation for patients with locally advanced HPV16-positive cervical cancer. Anticancer Res 32: 4319-4325, 2012.

33. Birner P, Schindl M, Obermair A, Plank C, Breitenecker G and Oberhuber G: Overexpression of hypoxia-inducible factor 1alpha is a marker for an unfavorable prognosis in early-stage invasive cervical cancer. Cancer Res 60: 4693-4696, 2000.

34. Vaupel P and Mayer A: Hypoxia in cancer: Significance and impact on clinical outcome. Cancer Metastasis Rev 26: 225-239, 2007.

35. Yen TC, See LC, Lai CH, Yah-Huei CW, Ng KK, Ma SY, Lin WJ, Chen JT, Chen WJ, Lai CR and Hsueh S: 18F-FDG uptake in squamous cell carcinoma of the cervix is correlated with glucose transporter 1 expression. J Nucl Med 45: 22-29, 2004

36. Kim BW, Cho H, Chung JY, Conway C, Ylaya K, Kim JH and Hewitt SM: Prognostic assessment of hypoxia and metabolic markers in cervical cancer using automated digital image analysis of immunohistochemistry. J Transl Med 11: 185, 2013.

37. Le QT and Courter D: Clinical biomarkers for hypoxia targeting. Cancer Metastasis Rev 27: 351-362, 2008. 